\title{
THE ADVANTAGE OF A HIGH PROTEIN DIET IN THE TREATMENT OF SPONTANEOUS HYPOGLYCEMIA
}

\author{
Preliminary Report \\ BY JEROME W. CONN \\ (From the Department of Internal Medicine, University of Michigan Medical School, \\ Ann Arbor)
}

Several clinical procedures for the control of paroxysmal spontaneous hypoglycemia have been advocated, but therapeutic results, for the most part, have been disappointing. It is our purpose to review briefly the present status of medical treatment and to present evidence in support of a dietary régime which is successful and appears to be justified from a theoretical point of view.

Since Harris (1) first described the clinical syndrome of hyperinsulinism in 1924 the condition has been recognized with increasing frequency. Many reviews $(2,3,4,5,6)$ comprising large numbers of cases have appeared in the more recent literature, due consideration having been given to both the medical and surgical aspects of the disease. Inasmuch as this report is concerned mainly with the treatment of the condition, a brief description of the clinical syndrome will suffice.

The disorder is characterized by the periodic occurrence of symptoms varying from weakness, hunger, trembling, excessive sweating, visual disturbances or giddiness, to temporary lapses in memory, changes in behavior and personality, convulsions and unconsciousness. These symptoms, which have come to be associated with hypoglycemia, are similar to those seen following the administration of an overdose of insulin. The symptoms usually occur three to four hours after meals or in the early hours of the morning. Patients often discover that the ingestion of food, particularly carbohydrate food, relieves the symptoms. The presence of an abnormally low blood sugar during an attack, and relief of the attack by ingested or intravenous glucose is sufficient to make the diagnosis. When, as is often the case, the physician fails to see the patient during an attack, the glucose tolerance test as a diagnostic aid is often helpful. Two to five hours after the ingestion of a standard amount of glucose ( 1.75 grams per kilo of body weight) these patients exhibit a precipitious fall in the blood sugar to hypoglycemic levels. It must be remembered, however, that the hypoglycemia obtained in this way may be of short duration and may be missed if the usual hourly blood samples only are taken. This point is illustrated in Figure 1 which represents one of the curves obtained in Case I described below. We have, therefore, modified the test somewhat by taking blood samples every thirty minutes after the second hour for two to three hours.

A survey of the literature reveals that if the pancreases of these patients are examined, either surgically or at autopsy, about 50 per cent are found to have pancreatic abnormalities. (This statement excludes those hypoglycemic states which are due to other pathological processes, such as diseases of the liver $(7,8)$, pituitary $(9)$, thyroid (10) or adrenal glands (11)). In the group which has abnormalities of the pancreas, islet cell carcinomas, adenomata of islet tissue and simply hypertrophy of the islets of Langerhans have been reported.

\section{Surgical treatment}

When an unquestioned clinical diagnosis has been made there appears to be a 50 per cent chance that a pancreatic abnormality will be found at laparotomy. Exploratory laparotomy, therefore, seems to be indicated, especially if the patient is in the cancer age and if symptoms have been progressive and of relatively short duration. If a pancreatic tumor has been found and removed surgically, results have been excellent, with complete cure in many cases (12). If a grossly normal pancreas has been found, partial pancreatectomy has been advised (13) and done in many cases, with disappointing results as far as alleviation of hypoglycemic attacks is concerned. 


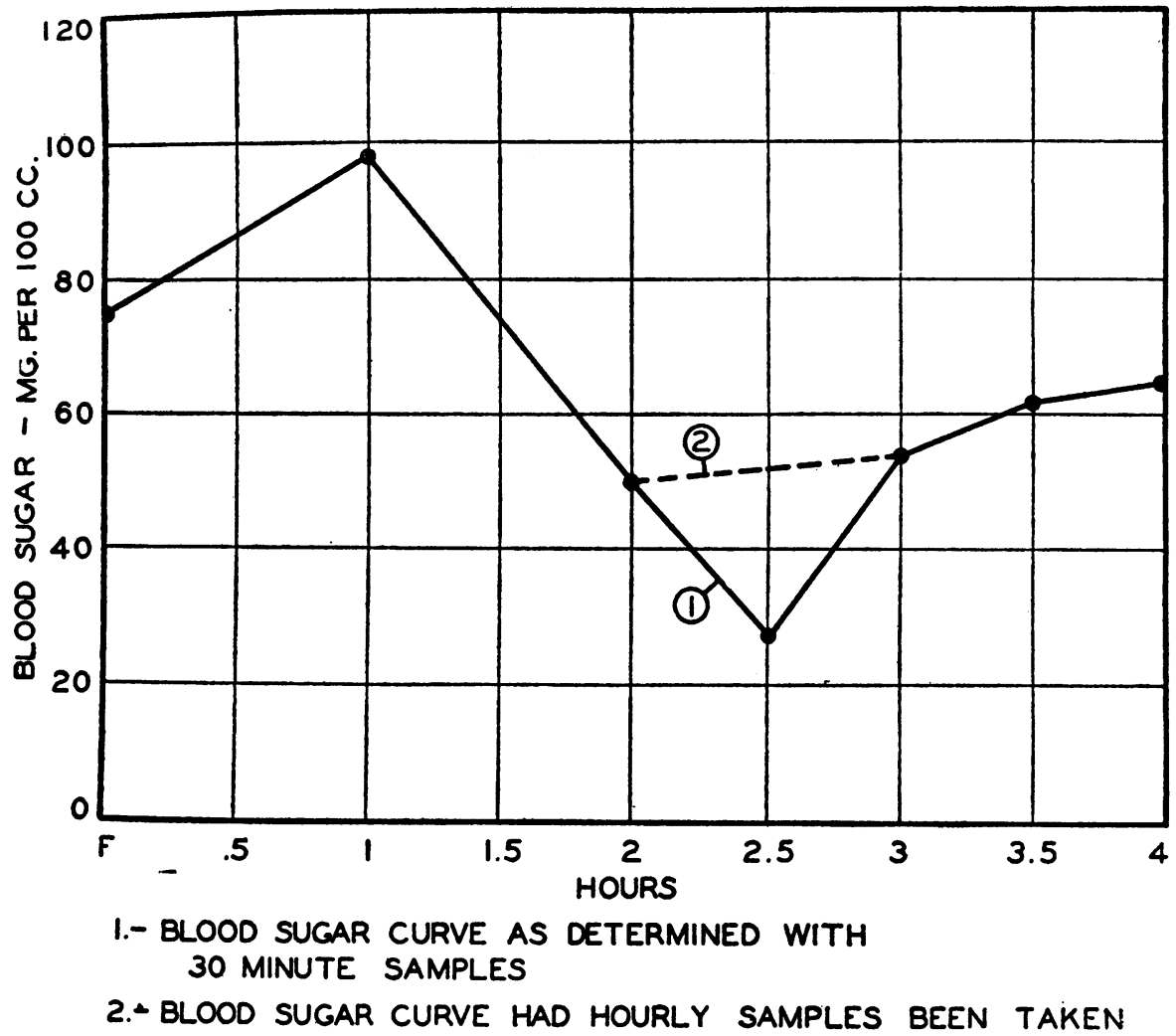

Fig. 1. Glucose Tolerance Test

\section{Medical treatment}

One is left, then, with a group of patients who must be treated by medical measures because operation is not advised, is refused, or has been performed without alleviation of symptoms. Three types of medical management have thus far been advocated. The first and most obvious method of treatment was a high carbohydrate diet, suggested by the patients' own observations that food relieved symptoms. It was reasoned that if the subject were suffering from an excessive production of pancreatic insulin, a large amount of carbohydrate in the diet would have a tendency to neutralize this effect. Again results were disappointing. While some of the patients improved on this régime, many were unimproved or actually were made worse (14). It was soon realized that the ingestion of carbohydrate afforded an extra stimulus to pancreatic formation of insulin, which is already being produced in excessive amounts. Experimental evidence supporting this observation is afforded by Len- nox (15). The pendulum then swung in the opposite direction and Waters (5) in 1931 advised strict curtailment of the carbohydrate in the diet, most of the calories being derived from fat. Following this a high fat, low carbohydrate diet with feedings divided into six daily meals was generally adopted. On this régime there was often prompt improvement; but while hypoglycemic attacks were diminished in number, they still occurred with alarming frequency.

The next and most recent therapeutic suggestion was that of John (16). He reasoned that if the sudden drop of the blood sugar to hypoglycemic levels was secondary to the pancreatic stimulation caused by the postprandial rise in blood sugar, then something which would prevent the hyperglycemia might also prevent the subsequent drop in blood sugar values. $\mathrm{He}$, therefore, uses a low carbohydrate diet divided into three meals and gives about ten units of insulin one-half hour after each meal. He reports good results. 
We (17) have shown that in both normals and diabetics the ingestion of large amounts of protein is followed by comparatively little or no rise in the blood sugar level. Yet protein during its metabolism yields approximately 50 per cent of its weight as glucose. When an equivalent amount of glucose is ingested as such or as carbohydrate food a significant hyperglycemia is produced.

Our interpretation of this difference in the glycemic response to isoglucogenic quantities of protein and carbohydrate is given in detail in the previous paper (17). Suffice it to say here that during the metabolism of protein, the large amount of glucose derived in this process is liberated into the blood stream at a slow and even rate over a prolonged period of time and fails to produce hyperglycemia.

It was realized, then, that the ingestion of large amounts of protein would supply glucose to the blood stream at a constant, slow rate, without the production of a hyperglycemia. This would be advantageous to the patient with hyperinsulinism in that it would not stimulate the insulogenic mechanism and yet would supply a source of glucose over a considerable period. The carbohydrate of the diet could be further restricted when necessary in severe cases. A large amount of glucose could be derived from protein. This glucose can be made available in sufficient amount to produce a fatty acid-glucose ratio that will prevent acidosis, even if no carbohydrate is included in the diet.

Three typical examples of spontaneous hypoglycemia were chosen for this study. All three came to the hospital complaining of attacks of convulsions and unconsciousness, symptoms which conform to the criteria, mentioned above, necessary for the diagnosis. ${ }^{1}$ One of the three which will be discussed in detail is Weil's (14) case reported as "functional hyperinsulinism" in 1932.

Case I (V. S.). On admission to the hospital a provisional diagnosis of spontaneous hypoglycemia was made. The following is the response to the routine glucose tolerance test (1.75 grams glucose per kilogram of body weight given orally).

1 Since it is not the purpose of this report to enlarge on diagnostic criteria, details of the case histories are intentionally omitted to conserve space.
Fasting ....... $74 \mathrm{mgm}$. sugar per $100 \mathrm{cc}$. blood 1 hour ......... $115 \mathrm{mgm}$. sugar per $100 \mathrm{cc}$. blood 2 hours ........ $70 \mathrm{mgm}$. sugar per $100 \mathrm{cc}$. blood 3 hours ........ 40 mgm. sugar per 100 cc. blood

A repetition of this test gave the following results :

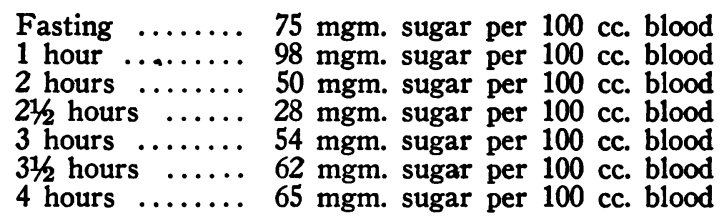

Figure 2 shows the comparative effects of ingestion of one gram of glucose per kilogram of body weight and 2 grams of protein per kilogram of body weight each yielding an equivalent amount of glucose in its metabolism. It is seen that after ingestion of glucose a hypoglycemic phase follows directly upon the hyperglycemic one. On the other hand, the curve following the ingestion of protein remains essentially flat over a period of eight hours. The gradual and prolonged rise of the blood urea nitrogen reflects the utilization of protein and the slow liberation of glucose into the blood stream.

Case II (W. L.). The history suggested spontaneous hypoglycemia. A routine glucose tolerance test gave the following response:

Fasting ...... $82 \mathrm{mgm}$. sugar per $100 \mathrm{cc}$. blood 1 hour ......... $208 \mathrm{mgm}$. sugar per $100 \mathrm{cc}$. blood 2 hours ........ $120 \mathrm{mgm}$. sugar per $100 \mathrm{cc}$. blood 3 hours ........ $30 \mathrm{mgm}$. sugar per $100 \mathrm{cc}$. blood

Figure 3 again demonstrates the absence of either hypoglycemia or hyperglycemia when the glucose is derived from protein. When, however, this same amount of glucose is given as such, both the hypoglycemic and hyperglycemic responses are obtained. The smaller amount of glucose ingested in this test probably accounts for the fact that the degree of pancreatic stimulation (15) and consequent hypoglycemia are less than those of the original test given above.

Case III (L. J.). This patient's early history with complete and thorough study is reported by Weil (14). This physician made the diagnosis of hyperinsulinism and prescribed treatment for this condition.

Briefly, a 32 year old, intelligent housewife, complained of faintness and weakness, occasionally accompanied by convulsions and unconscious spells, beginning in October, 1930. There have been 35 to 40 convulsive attacks since that time. Very low blood sugar values were found during attacks. She frequently returned to a normal state within a few minutes after glucose was given either intravenously or by mouth. Often when actual convulsions did not occur there were periods of weakness, trembling, sensorial clouding, loss of memory and giddiness. Although attacks usually occurred during sleep in the early hours of the morning, they sometimes came on during the day, three to four hours after the preceding meal. The attacks were frequently centered about the week of catamenia, although they had occurred at any time of the month. 


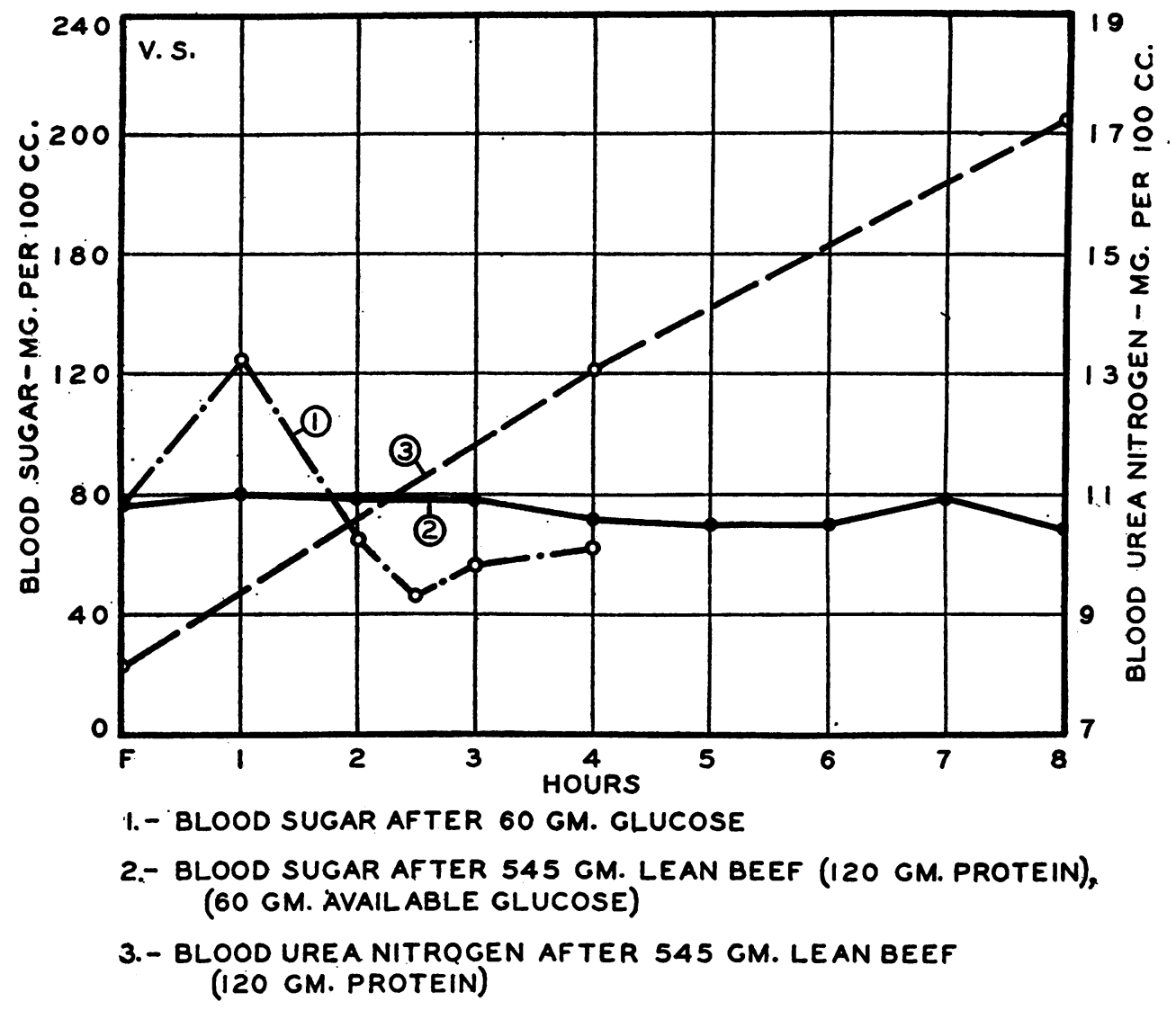

Fig. 2. Blood Sugar and Blood Urea Nitrogen Curves in Case I

A relatively high carbohydrate diet had failed to effect improvement and had made the patient worse. A low carbohydrate, high fat diet (60 grams of protein, 250 grams of fat and 100 grams of carbohydrate) divided into 5 or 6 equal feedings prescribed by Weil improved the symptoms and reduced the frequency of attacks, but the patient was not relieved of these episodes.

She came to the University Hospital on October 18, 1935 , stating that in spite of rigid adherence to her weighed diet her attacks were becoming more frequent and alarming. Between attacks she noticed marked faintness, restlessness and memory difficulty. Exploratory laparotomy was discussed with the patient, but not urged.

The blood sugar curves following ingestion of equivalent amounts of glucose as such and as derived from protein are shown in Figure 4. Following glucose ingestion a rise in the blood sugar is followed by a precipitous fall to $39 \mathrm{mgm}$. per $100 \mathrm{cc}$. After ingestion of protein, however, the blood sugar curve remained flat for an 8 hour period. The rise of the blood urea nitrogen again signifies protein utilization. It will be noted that there was very little drop in the blood sugar in the fasting state. It appears, then, that the hyperglycemia produced by the ingestion of glucose affords the stimulus for the secretion of insulin, which results in the secondary hypoglycemia.
On February 7, 1936, the patient was instructed to use a diet containing 110 grams of protein, 150 grams of fat and 50 grams of carbohydrate, yielding a total of 2000 calories. It was felt from the experience with experimental periods, that the glucose would be delivered slowly over a sufficiently prolonged period to allow freedom from attacks even if only three meals a day were given. The diet, therefore, was divided into three equal meals to be taken at the usual times.

More than three months have elapsed. The patient has had no convulsions. She reports that she has felt much better in all respects. She no longer has the periods of faintness, weakness, restlessness and trembling complained of during the years of treatment with other dietary plans.

\section{CONCLUSIONS}

1. The slow rate at which glucose is liberated into the blood stream during the metabolism of protein is of advantage in the treatment of spontaneous hypoglycemia because-

(a) It causes no hyperglycemia and thus avoids excessive production of insulin and secondary hypoglycemia. 


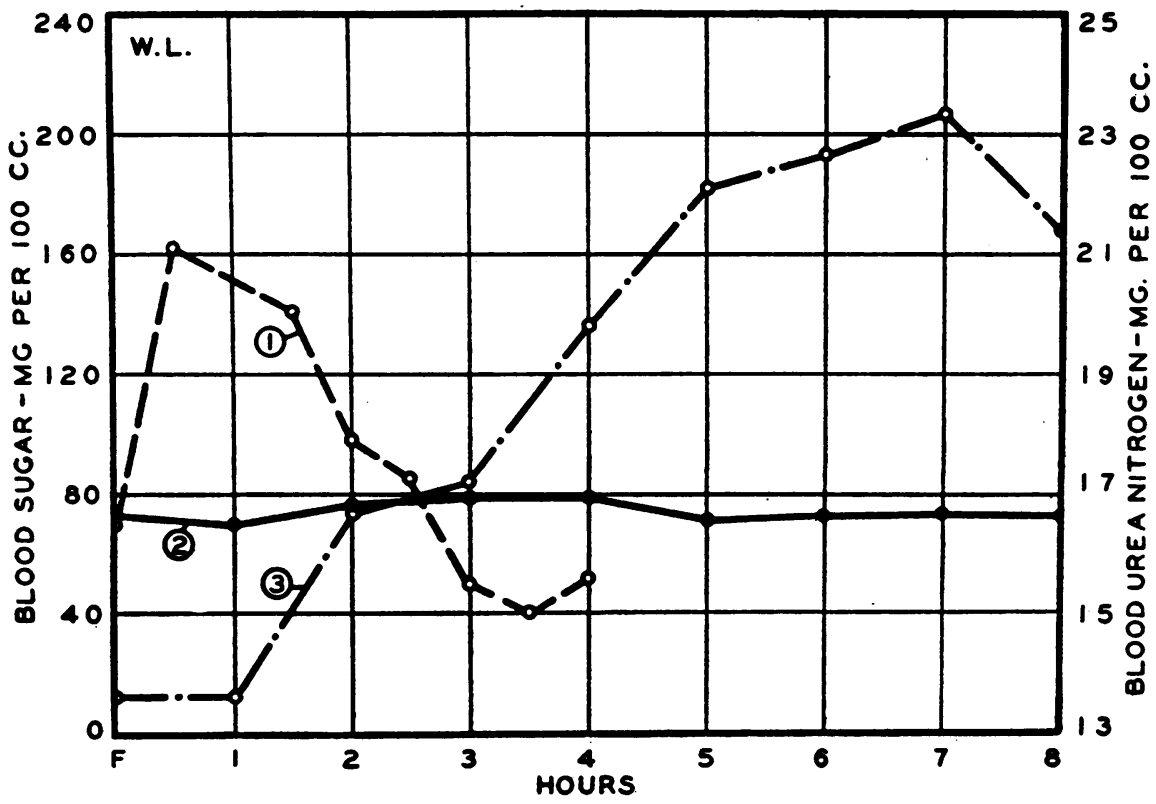

I. - BloOd SUGAR AFTER 57 GM. GLUCOSE

2.- BLOOD SUGAR AFTER 518 GM. LEAN BEEF ( 114 GM. PROTEIN), (57 GM. AVAIL ABLE GLUCOSE)

3. - BLOOD UREA NITROGEN AF TER 518 GM. LEAN BEEF (114 GM. PROTEIN)

Fig. 3. Blood Sugar and Blood Urea Nitrogen Curves in Case II

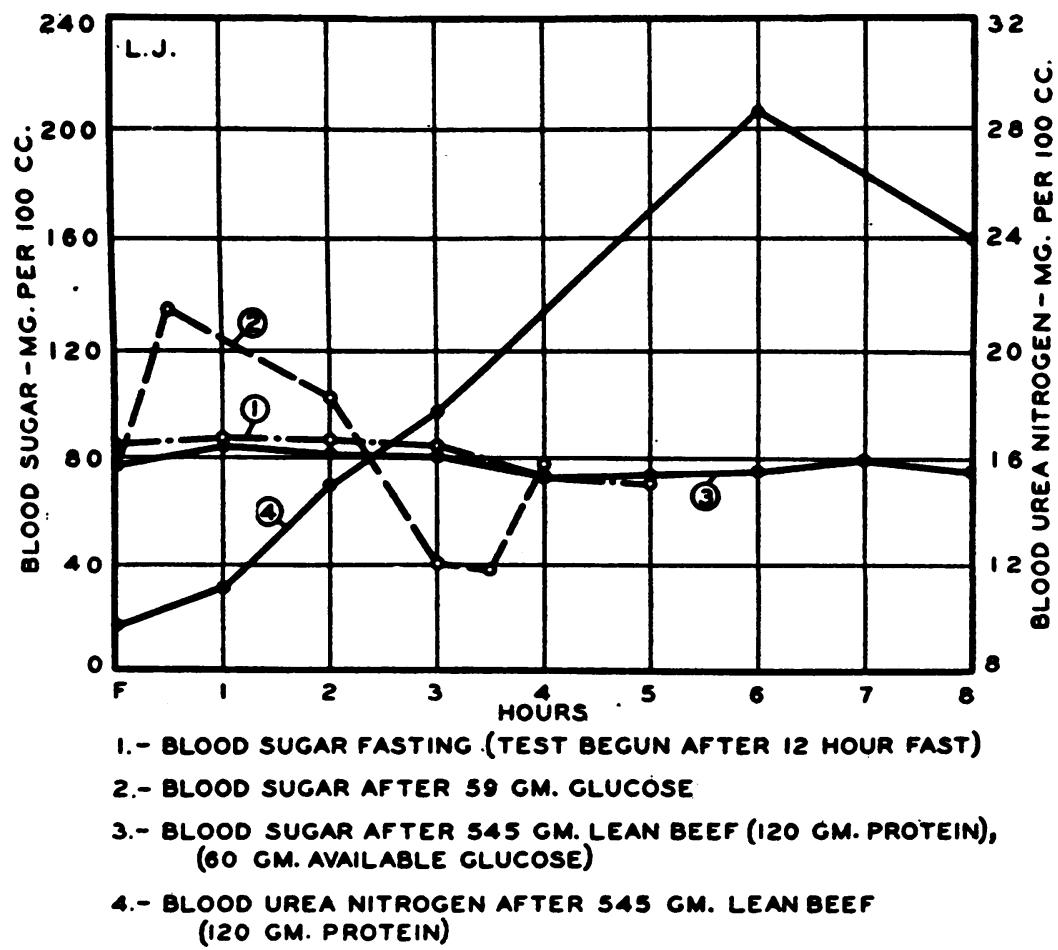

Fig. 4. Blood Sugar and Blood Urea Nitrogen Curves in Case III 
(b) It provides a source of glucose over a prolonged period of time.

(c) It allows in severe cases further restriction in carbohydrate than could otherwise be effected.

2. These facts justify the use of a diet high in protein and low in carbohydrate in the treatment of this condition.

\section{BIBLIOGRAPHY}

1. Harris, S., Hyperinsulinism and dysinsulinism. J. A. M. A., 1924, 83, 729.

2. Graham, E. A., and Womack, N. A., The application of surgery to the hypoglycemic state due to islet tumors of the pancreas and to other conditions. Surg., Gynec. and Obst., 1933, 56, 728.

3. Wilder, R. M., Hyperinsulinism. Internat. Clin., 1933, $2,1$.

4. Judd, E. S., Allan, F. N., and Rynearson, E. H., Hyperinsulinism; Its surgical treatment. J. A. M. A., 1933, 101, 99.

5. Waters, W. C., Jr., Spontaneous hypoglycemia; The rôle of diet in etiology and treatment. South. M. J., 1931, 24, 249.

6. Whipple, A. O., and Frantz, V. K., Adenoma of islet cells with hyperinsulinism. Ann. Surg., 1935, 101, 1299.

7. Cross, J. B., and Blackford, L. M., Fatal hepatogenic hypoglycemia following neoarsphenamine. J. A. M. A., 1930, 94, 1739.
8. Nadler, W. H., and Wolfer, J. A., Hepatogenic hypoglycemia associated with primary liver cell carcinoma. Arch. Int. Med., 1929, 44, 700.

9. Wilder, J., Ein neues hypophysäres Krankheitsbild: Die Hypophysäre spontanhypoglykämie. Deutsche Ztschr. f. Nervenh., 1930, 112, 192.

10. Zubiran, S., Sobre un caso de hipoglicemia. Medicina, Mexico, 1929, 9, 306.

11. Anderson, H. B., A tumor of the adrenal with fatal hypoglycemia. Am. J. M. Sc., 1930, 180, 71.

12. Carr, A. D., Parker, R., Grove, E., Fisher, A. O., and Larimore, J. W., Hyperinsulinism from B-cell adenoma of the pancreas: operation and cure. J. A. M. A., 1931, 96, 1363.

13. Holman, E., and Railsback, O. C., Partial pancreatectomy in chronic spontaneous hypoglycemia. Surg., Gynec. and Obst., 1933, 56, 591.

14. Weil, C. K., Functional hyperinsulinism; Epileptiform convulsions accompanying spontaneous hypoglycemia. Internat. Clin., 1932, 4, 33.

15. Lennox, W. G., Stimulation of the sugar regulating mechanism as shown by duplicate blood sugar curves. J. Biol. Chem., 1927, 73, 237.

16. John, H. J., A case of hyperinsulinism treated with insulin; Preliminary report. Endocrinology, 1933, 17, 583.

17. Conn, J. W., and Newburgh, L. H., The glycemic response to isoglucogenic quantities of protein and carbohydrate. J. Clin. Invest., 1936, 15, 665. 